\title{
Toe flexor strength and foot morphology in older people requiring long-term care due to changes in their means of mobilizing in daily life: a cross- sectional study
}

Mieko Yokozuka ( $\square$ yokozuka@fmu.ac.jp )

Fukushim Medical University

Sei Sato

Fukushima Medical University

Research

Keywords: toe flexor strength, foot morphology, dependent elderly, wheelchair, mobilization

Posted Date: October 8th, 2020

DOI: https://doi.org/10.21203/rs.3.rs-88646/v1

License: (c) (i) This work is licensed under a Creative Commons Attribution 4.0 International License. Read Full License

Version of Record: A version of this preprint was published on March 12th, 2021. See the published version at https://doi.org/10.1186/s13047-021-00458-8. 


\section{Abstract}

Background: Hallux valgus and lesser toe deformity reduce the strength of the toe flexors and are a cause of falls in older people. This study aimed to examine the differences in toe flexor strength and foot morphology in older people requiring long-term care due to changes in the way they mobilize in everyday life.

Methods: Eighty-four people aged $\geq 70$ without motor paralysis who are undergoing or had undergone ambulatory rehabilitation. They were divided into those who could mobilize without a wheelchair (walking group, $n=54$ ) and those who used a wheelchair to mobilize (wheelchair group, $n=30$ ). Presence of diseases, hand grip strength, toe flexor strength, and foot morphology were compared between the two groups.

Results: No significant between-group difference in foot morphology was found. Factors related to differences in the means used to mobilize in daily life were a history of fracture, heart disease, and toe flexor strength. In muscle strength of the wheelchair group compared with the mean values of the walking group, the toe flexor strength was significantly more decreased in relation to hand grip strength.

Conclusions: Older people who use a wheelchair to mobilize have significantly less toe flexor strength than those who do not despite having no significant difference in foot morphology. Use of a wheelchair is associated with a reduction in toe flexor strength.

\section{Background}

The reported odds ratio for falls ranges from 1.67 to 1.95 in community-dwelling older people with foot problems, such as foot pain, hallux valgus, and lesser toe deformity (1). In a meta-analysis, the prevalence of hallux valgus in people aged $\geq 65$ years was $35.7 \%$ (2). Hallux valgus was found in $28.4 \%$ of older Japanese people living in the community (3). Furthermore, more than $50 \%$ of 18 older adults who use day care services for assistance in daily life have hallux valgus (4). Although many studies have focused on the foot morphology of community-dwelling older people, there are only a few reports about this issue in older people requiring long-term care. Therefore, the foot morphology and toe muscle strength of the frail elderly who need long-term nursing care are unknown.

Hallux valgus and lesser toe deformity significantly reduce plantar flexor strength in the hallux and lesser toes in older people (5). The plantar flexor strength of the hallux and lesser toes has been associated with balance and functional ability in older adults $(6,7)$. Moreover, strength of toe flexor is correlated with spatiotemporal gait parameters in community-dwelling older people (8). The hallux and lesser toe deformities and the subsequent reduction of their muscles affect functional ability, so these issues must be prevented.

As for the associations between toe flexor strength and foot structure, correlations have been reported between toe flexor strength and the medial longitudinal arch height (9), toe curl activity (10), and hallux 
valgus angle (11). In contrast, no correlation has been reported between toe flexor strength and foot morphology, and correlations have been reported between the hallux valgus angle, arch height, and spread ratio (12). The subjects of these studies varied in terms of gender, age, and activity level. The causal relationship between the hallux valgus angle and toe flexor strength is unknown; however, the difference in decline of toe flexor strength leads to a low medial longitudinal arch height and a high spread ratio, and these may be factors involved in hallux valgus.

Toe flexor strength correlates positively with the number of steps taken per day (13). Therefore, there may be differences in toe flexor strength and foot morphology between those who use a wheelchair to move about and those who walk without a wheelchair. If toe flexor weakness is a cause of foot deformity, a difference in decline of strength could lead to a difference in deformation of the foot in older persons. And if there is such a difference, interventions to maintain toe flexor strength and prevent foot deformity may be necessary, even in a person using a wheelchair, so that they can perform everyday activities safely while standing.

This study aimed to investigate toe flexor strength and foot morphology according to the means used to move about in everyday life in frail older people requiring long-term care. If toe flexor strength and foot morphology differ depending on the means of movement, weakness of muscle strength may affect foot morphology. In addition, we investigated the factors that affect the means of movement and the extent of decline in strength, and we considered those factors for future prevention measures.

\section{Methods}

\section{Participants}

This cross-sectional study of people aged $\geq 70$ years who needed assistance with everyday activities and had received or were undergoing ambulatory rehabilitation in a long-term health care facility was conducted from January 2020 to April 2020. The study exclusion criteria were motor paralysis, inability to stand with assistance, and inability to understand simple instructions during measurement of muscle strength and foot morphology. The study was approved by our University Ethics Committee (approval number 30293). All participants provided written informed consent after receiving a written and verbal explanation of the purpose of the study.

\section{Evaluation}

Toe flexor strength was measured using a toe grip dynamometer (T.K.K.3364b, Takei Scientific Instruments Co., Ltd. Niigata, Japan). The hip, knee, and ankle joints were set at $90^{\circ}$ in the chair sitting position, and the ankle joint was fixed with a belt at a position where the bar to be measured could be easily gripped by the toes. The measurement was repeated three times on each side with the bar gripped firmly by the toes. Hand grip strength was measured to compare the proportion of reduction in toe flexor strength using a hand grip dynamometer (T.K.K. 5401, Takei Scientific Instruments Co., Ltd. Niigata, Japan). Measurements were taken twice each on both sides in the chair sitting position with both upper 
limbs dropped to the sides. The values for toe flexor strength and hand grip strength divided by body weight were used in the analysis to correct for physique.

For measurement of foot morphology, being mindful of safety, the participant weight was evenly applied to both soles of the feet while sitting on a chair, and the foot contour was taken using a foot printer (Bauerfeind, Zeulenroda-Triebes, Germany). The angle formed by the first phalanx and the first metatarsal bone was measured using a foot contour to obtain the hallux valgus angle. Hallux valgus was present if this angle was $\geq 16^{\circ}$ (14). For the medial longitudinal arch, the height of the scaphoid tubercle from the floor was measured with a right-angle ruler and divided by the foot length to calculate the arch height ratio in the chair sitting position. For the lateral arch, the spread ratio was calculated by dividing the width of the foot by its length. Foot width and length were read from the foot contour.

All measurements were performed by a physical therapist who was in daily contact with the participants and able to communicate with them well.

\section{Statistical analysis}

The participants were divided into a wheelchair group (using a wheelchair to move about in daily life) and a walking group (walking without a wheelchair). Toe flexor strength and foot morphology were analyzed on the side with the greater hallux valgus angle when this angle was $\geq 16^{\circ}$ on one side or both sides. If the angle was $<16^{\circ}$ on both left and right sides, the side to be analyzed was chosen using the random number method (15). For hand grip strength, the maximum value obtained for the left and right sides was used for the analysis. The distributions of participant gender, presence or absence of disease, and hallux valgus in at least one foot were compared using Pearson's chi-square test. Normality was examined by the Shapiro-Wilk test. Age, hand grip strength, toe flexor strength, and foot morphology were compared using the unpaired t-test or Mann-Whitney $\mathrm{U}$ test. Multiple logistic regression analysis with the forward stepwise selection (likelihood ratio) method was performed using the means of movement as the dependent variable and participant age and gender, diseases with significant between-group differences, toe flexor strength, and foot morphology as explanatory variables. To investigate the degree of reduction in toe flexor strength, the paired t-test was used to compare differences in the mean hand grip strength and toe flexor strength values between the wheelchair group and the walking group. All statistical analyses were performed using SPSS for Windows, version 25 (IBM Corp., Armonk, NY, USA). The significance level was set to $5 \%$.

\section{Results}

Eighty-four older individuals ( 25 males, 59 females), with a mean age of $86.4 \pm 6.0$ years and a mean body mass index of $20.7 \pm 3.5$, participated in the study. Table 1 shows the participant characteristics and measurements obtained. Significant differences in the fracture rate $(p=0.028)$ and frequency of heart disease $(p=0.005)$ and in toe flexor strength $(p<0.001)$ were found between the two groups. At least one foot had hallux valgus in $50 \%(n=27)$ of the walking group members and $53.3 \%(n=16)$ of the 
wheelchair group members. No significant difference was noted in the foot morphology between the two groups.

\begin{tabular}{|c|c|c|c|c|}
\hline & $\begin{array}{l}\text { Walking group } \\
n=54\end{array}$ & $\begin{array}{l}\text { Wheelchair group } \\
n=30\end{array}$ & $\mathrm{p}$-value & $\beta$ \\
\hline Age & $85.78 \pm 6.74$ & $87.40 \pm 4.45$ & 0.241 & 0.766 \\
\hline Female, n (\%) & $36(66.7)$ & $23(76.7)$ & 0.337 & 0.830 \\
\hline Height & $150.19 \pm 8.58$ & $149.08 \pm 7.43$ & 0.551 & 0.907 \\
\hline Weight & $47.41 \pm 10.59$ & $45.61 \pm 8.70$ & 0.447 & 0.876 \\
\hline \multicolumn{5}{|l|}{ Disease, n (\%) } \\
\hline Bone and joint & $27(50.0)$ & $15(50.0)$ & 1.000 & 0.950 \\
\hline Fracture & $19(35.2)$ & $18(60.0)$ & 0.028 & 0.388 \\
\hline Cerebrovascular & $15(27.8)$ & $9(30.0)$ & 0.829 & 0.945 \\
\hline Heart & $7(13.0)$ & $12(40.0)$ & 0.005 & 0.181 \\
\hline Dementia & $26(48.1)$ & $10(33.3)$ & 0.189 & 0.728 \\
\hline Mental illness & $3(5.6)$ & $2(6.7)$ & 0.837 & 0.945 \\
\hline Hand grip strength $\left(\mathrm{kg} / \mathrm{bw} w^{*} 100\right)$ & $33.54 \pm 9.38$ & $24.90 \pm 7.52$ & $<0.001$ & 0.007 \\
\hline Toe flexor strength $(\mathrm{kg} / \mathrm{bw} * 100)$ & $9.57 \pm 4.45$ & $5.60 \pm 3.11$ & $<0.001$ & 0.006 \\
\hline \multicolumn{5}{|l|}{ Foot morphology } \\
\hline Hallux valgus, $\mathrm{n}(\%)$ & $27(50.0)$ & $16(53.3)$ & 0.770 & 0.940 \\
\hline Hallux valgus angle & $16.61 \pm 11.17$ & $19.30 \pm 10.46$ & 0.193 & 0.816 \\
\hline Arch high rate & $22.06 \pm 3.10$ & $21.43 \pm 3.08$ & 0.375 & 0.857 \\
\hline Spread ratio & $41.06 \pm 3.04$ & $42.10 \pm 2.36$ & 0.135 & 0.634 \\
\hline \multicolumn{5}{|l|}{ bw, body weight } \\
\hline Hand grip strength could not be & asured for one & erson in the walkin & group. & \\
\hline
\end{tabular}

Table 2 shows the results of the multiple logistic analysis using the means of mobility as the dependent variable, with history of fracture, heart disease, toe flexor strength, and foot morphology as explanatory 
variables. As a result, fracture, heart disease, and toe flexor strength were significant determinants of the means of mobility.

\section{Table 2}

Factors affecting the means of mobility identified in the multiple logistic regression analysis

\begin{tabular}{|c|c|c|c|c|c|}
\hline & \multirow{2}{*}{$\begin{array}{l}\text { Partial regression } \\
\text { coefficient }\end{array}$} & \multirow{2}{*}{$\begin{array}{l}\mathrm{p}- \\
\text { value }\end{array}$} & \multirow{2}{*}{$\begin{array}{l}\text { Odds } \\
\text { ratio }\end{array}$} & \multicolumn{2}{|c|}{$95 \%$ confidence interval } \\
\hline & & & & $\begin{array}{l}\text { Lower } \\
\text { limit }\end{array}$ & $\begin{array}{l}\text { Upper } \\
\text { limit }\end{array}$ \\
\hline Fracture & 1.732 & 0.006 & 5.650 & 1.627 & 19.626 \\
\hline Heart disease & 1.622 & 0.018 & 5.063 & 1.319 & 19.442 \\
\hline $\begin{array}{l}\text { Toe flexor } \\
\text { strength }\end{array}$ & -0.302 & 0.000 & 0.739 & 0.624 & 0.876 \\
\hline Constant & 0.415 & 0.527 & 1.514 & & \\
\hline \multicolumn{6}{|c|}{ model chi-square test, $\mathrm{p} \otimes 0.001$} \\
\hline \multicolumn{6}{|c|}{ percentage of correct classifications, $77.4 \%$} \\
\hline
\end{tabular}

Table 3 shows the proportional differences in muscle strength of the wheelchair group compared with the mean values of the walking group. In the wheelchair group, the ratios of hand grip strength and toe flexor strength were $74.24 \pm 22.42 \%$ and $58.50 \pm 32.58 \%$, respectively, and the toe flexor strength was significantly decreased when compared with the hand grip strength $(p=0.002)$.

\section{Table 3 Proportional differences in muscle strength in the wheelchair group compared with the mean values of walking group}

\begin{tabular}{|lllll|}
\hline & $\begin{array}{l}\text { Hand grip } \\
\text { strength }\end{array}$ & $\begin{array}{l}\text { Toe flexor } \\
\text { strength }\end{array}$ & $\begin{array}{l}\mathrm{p} \text { - } \\
\text { value }\end{array}$ & $\beta$ \\
\hline $\begin{array}{l}\text { Proportional difference from walking } \\
\text { mean, \% }\end{array}$ & $74.24 \pm 22.42$ & $58.50 \pm 32.58$ & 0.002 & 0.176 \\
\hline
\end{tabular}

\section{Discussion}

This cross-sectional study examined the differences in toe flexor strength and foot morphology between older individuals who use a wheelchair and those who walk when moving about in everyday life. We found that older people who used a wheelchair were more likely to have a history of fracture or heart disease and weaker toe flexor strength. A wheelchair is often used when it is difficult to walk. However, these study participants did not have motor paralysis and were capable of standing with or without assistance, but they could not walk safely. A history of bone fracture or heart disease had a significant 
negative effect on the likelihood of walking. However, it is unclear whether the participants who used a wheelchair did so because of joint contracture subsequent to a fracture or because of disuse atrophy associated with heart disease, or whether the turning point for using a wheelchair was disuse as a result of other diseases.

In this study, no significant between-group difference was found in the foot morphology, including for hallux valgus; even in the multiple logistic regression analysis, foot morphology was not among the significant factors. The prevalence of hallux valgus detected on radiographs in older Japanese men and women living in the community was $28.4 \%$ (3) and that in day care service users was $>50 \%$ (4). In this study, hallux valgus was found in about half of the older participants who needed some assistance with activities of daily living and are undergoing or had received ambulatory rehabilitation in a long-term care health facility. This percentage was higher than that in community-dwelling older people and tended to be similar to that in day care users.

Toe flexor strength was significantly greater in the walking group than in the wheelchair group. The strength of the toe flexors is related to walking parameters such as walking speed (8) and the timed up and go test (16). In particular, a positive correlation between toe flexor strength and the average number of steps taken per day was reported in women aged $>80$ years (13). Hallux valgus and lesser toe deformity reduce the strength of plantar flexion $(5,17,18)$. In our study, no significant difference was found in the foot morphology between the two groups; however, toe flexor strength was significantly greater in the walking group and was attributed to a difference in the amount of activity performed when standing, including walking. Since there is no difference in foot morphology even when muscle strength is significantly reduced, muscle weakness is unlikely to cause changes in foot morphology.

With regard to the proportion of each muscle strength of the wheelchair group to the mean values of toe flexor strength and hand grip strength in the walking group, the proportion of toe flexor strength was significantly lower than the proportion of hand grip strength. With age, the skeletal muscle mass in the lower limbs is significantly less on magnetic resonance images than that in the upper limbs (19). Furthermore, the ratio of muscle thickness in older people to that in young people was significantly lower in the plantar flexors than in the elbow flexors (20) and there was a significant decrease in the ratio of reduction in toe flexor strength to hand grip strength $(21,22)$. The results of this study suggest that the standing and walking frequencies had some influence on the values because no difference was found in age between the walking group and the wheelchair group.

A study has reported that the toe flexor muscles and ankle range of motion are important for balance while standing and for functional ability (6). Wheelchair users have significantly less toe flexor strength, which may affect balance when standing. Even when using a wheelchair as a means of mobility in daily living, in order to stand, turn, and sit safely when transferring from a wheelchair, if there is no severe motor paralysis of the lower limbs, joint contracture, or load limitation, the person must be able to stand and may need to maintain toe flexor strength. 
This study has several limitations, First, the foot morphology was measured from the contour of the foot; therefore, the influence of edema due to heart disease and involvement of pronation or supination of the ankle joint due to loading on the sole of the foot in the sitting position could not be determined. Second, the reason for using a wheelchair to mobilize in daily living and the duration of wheelchair use are unknown, so it is impossible to exclude factors of functional deterioration other than the foot and toes. Third, the proportion of male participants was lower than that of female participants, so the effect of gender differences was unknown.

\section{Conclusions}

In conclusion, about half of the older people requiring long-term care had hallux valgus. In this study, we found no difference in the foot morphology between those who use a wheelchair and those who do not use it as a means of moving in daily life, but a difference in toe flexor strength was found between them. The reduction in the toe flexor strength of people using a wheelchair was more remarkable than the reduction in the hand grip strength. Even when using a wheelchair in daily life, it is necessary to maintain the toe flexor strength in order to perform a safe standing motion.

\section{Declarations}

\section{Ethics approval and consent to participate}

The study was approved by our University Ethics Committee (approval number 30293).

\section{Consent for publication}

Not applicable

\section{Competing interests}

Sei Sato is employed by one of the healthcare facilities for the elderly. The other author declares no conflict of interest.

\section{Funding}

Research funds allocated from the University were used.

\section{Authors' contributions}

MY participated in the study design, analysis, interpretation and drafting of the manuscript. SS participated in the acquisition of participants, data acquisition, and assisted with data acquisition. All authors read and approved the final manuscript.

\section{Acknowledgements}


We thank all the participants in the study.

\section{References}

1. Menz HB, Auhl M, Spink MJ. Foot problems as a risk factor for falls in community-dwelling older people: a systematic review and meta-analysis. Maturitas 2018; 118:7-14.

2. Nix S, Smith M, Vicenzino B. Prevalence of hallux valgus in the general population: a systematic review and meta-analysis. J Foot Ankle Res 2010;3:21.

3. Nishimura A, Ito N, Nakazora S, Kato K, Ogura T, Sudo A. Does hallux valgus impair physical function? BMC Musculoskelet Disord. 2018;19(1):174. doi: 10.1186/s12891-018-2100-0.

4. Fujii K. Effect of foot care interventions for older adults using day care services. Nurs Open 2019;6:1372-1380.

5. Mickle KJ, Munro BJ, Lord SR, Menz HB, Steele JR. ISB Clinical Biomechanics Award 2009: toe weakness and deformity increase the risk of falls in older people. Clin Biomech (Bristol, Avon) 2009;24:787-791.

6. Spink MJ, Fotoohabadi MR, Wee E, Hill KD, Lord SR, Menz HB. Foot and ankle strength, range of motion, posture, and deformity are associated with balance and functional ability in older adults. Arch Phys Med Rehabil 2011;92:68-75.

7. Menz HB, Morris ME, Lord SR. Foot and ankle characteristics associated with impaired balance and functional ability in older people. J Gerontol A Biol Sci Med Sci 2005;60:1546-1552.

8. Misu S, Doi T, Asai T, Sawa R, Tsutsumimoto K, Nakakubo S, et al. Association between toe flexor strength and spatiotemporal gait parameters in community-dwelling older people. J Neuroeng Rehabil 2014;11:143.

9. Nagano K, Okuyama R, Taniguchi N, Yoshida T. Gender difference in factors affecting the medial longitudinal arch height of the foot in healthy young adults. J Phys Ther Sci 2018;30:675-679.

10. Uritani D, Fukumoto T, Matsumoto D, Shima M. Associations between toe grip strength and hallux valgus, toe curl ability, and foot arch height in Japanese adults aged 20 to 79 years: a cross-sectional study. J Foot Ankle Res 2015;8:18.

11. Yokozuka M, Okazaki K, Sakamoto Y, Takahashi K. Correlation between functional ability, toe flexor strength, and plantar pressure of hallux valgus in young female adults: a cross-sectional study. $J$ Foot Ankle Res. 2020 Aug 7;13(1):51. doi: 10.1186/s13047-020-00411-1. Erratum to: J Foot Ankle Res. 2020;13(1):44.

12. Yokozuka M, Miki C, Kurogo H, Kobayashi T, Nagai M, Katsura R. Foot characteristics and falls among community-dwelling independent elderly women who can walk outdoors. Progress in Rehabilitation Medicine. 2019; 4. doi: 10.2490/prm.20190017

13. Yokozuka M, Miki C, Suzuki M, Katsura R. Association between toe flexor strength and activity levels in community-dwelling Japanese older women. J Aging Phys Act 2019 12:1-5. doi: 10.1123/japa.2018-0217 
14. Shimizu S, Maeda T, Kato Y, Sasaki K, Uchida T. Effective evaluation of hallux valgus angle and digitus quintus varus angle for footprint. J Jpn Soc Surg Foot 2010;31:35-39. (in Japanese with English abstract).

15. Menz HB. Two feet, or one person? Problems associated with statistical analysis of paired data in foot and ankle medicine. The Foot 2004;14:2-5.

16. Uritani $D$, Fukumoto $T$, Matsumoto $D$, Shima M. The relationship between toe grip strength and dynamic balance or functional mobility among community-dwelling Japanese older adults: a crosssectional study. J Aging Phys Act 2016;24:459-464.

17. Nix SE, Vicenzino BT, Smith MD. Foot pain and functional limitation in healthy adults with hallux valgus: a cross-sectional study. BMC Musculoskelet Disord 2012;13:197.

18. Hurn SE, Vicenzino B, Smith MD. Functional impairments characterizing mild, moderate, and severe hallux valgus. Arthritis Care Res (Hoboken) 2015;67:80-88.

19. Janssen I, Heymsfield SB, Wang ZM, Ross R. Skeletal muscle mass and distribution in 468 men and women aged 18-88 yr. J Appl Physiol (1985) 2000;89:81-88.

20. Candow DG, Chilibeck PD. Differences in size, strength, and power of upper and lower body muscle groups in young and older men. J Gerontol A Biol Sci Med Sci 2005;60:148-156.

21. Suwa M, Imoto T, Kida A, Yokochi T. Early reduction in toe flexor strength is associated with physical activity in elderly men. J Phys Ther Sci 2016;28:1472-1477.

22. Suwa M, Imoto T, Kida A, Iwase M, Yokochi T. Age-related reduction and independent predictors of toe flexor strength in middle-aged men. J Foot Ankle Res 2017;10:15. 